\title{
APRENDIZAGEM DE PORTUGUÊS COMO LÍNGUA ESTRANGEIRA COM USO DO FACEBOOK E SOB A ORIENTAÇÃO DE COMUNIDADE DE BUSCA DO CONHECIMENTO
}

\section{Learning Portuguese as a foreign language using Facebook and under the guidance of Community of Inquiry}

\author{
Luís Eduardo WEXELL-MACHADO ${ }^{1}$
}

RESUMO: Este artigo descreve uma enquete, de forma comparativa, sobre a predisposição de estudantes para o uso de redes sociais na educação e analisa o uso do Facebook, como Comunidade de Busca do Conhecimento (Community of Inquiry), para o ensino de português como Língua Estrangeira para alunos de nível superior da Universidade Nacional de Assunção - Paraguai. O objetivo do estudo foi articular a aprendizagem do português como língua estrangeira com o desenvolvimento das habilidades digitais dos estudantes. Utilizou-se de uma abordagem qualitativa, estudo de caso, para descrever e analisar a produção e interação dos estudantes no uso da rede social como ambiente de aprendizagem.

PALAVRAS-CHAVE: Português como língua estrangeira; Letramento digital; Comunidade de Busca do Conhecimento.

ABSTRACT: This article describes a survey, in a comparative way, on the predisposition of students to the use of social networks in education and analyzes the use of Facebook as a Community of Inquiry in teaching Portuguese as a foreign language for higher education students of the Asuncion National University - Paraguay. The objective of this study was to articulate learning Portuguese as a foreign language with the development of the digital students' skills. This research was based on a qualitative approach, case study, to describe the production and interaction of the students in the use of this social network as a learning environment.

KEYWORDS: Portuguese as a foreign language; Digital Literacy; Community of Inquiry.

\footnotetext{
${ }^{1}$ Professor de português como língua estrangeira na Universidade Nacional de Assunção, Paraguai. Participante do Grupo de Pesquisa Prodesse e pesquisador da Universidade Autônoma de Assunção, Paraguai. lewmachado@gmail.com
} 


\section{INTRODUÇÃO}

Este trabalho teve como propósito articular a aprendizagem do português como língua estrangeira por estudantes de cursos de nível superior da Universidade Nacional de Assunção, Paraguai, com a prática e desenvolvimento de habilidades relacionadas com o meio digital, especificamente com práticas de leitura e escrita utilizando a rede social Facebook como Comunidade de Busca do Conhecimento (GARRISON, ANDRESON e ARCHER, 2000).

De acordo com Ribeiro (2010), todo e qualquer processo de leitura deve estar associado com o contexto em que tal processo ocorre, por se tratar de uma prática social, e com o meio que lhe serve de suporte e com o qual conjuntamente constrói significados.

No caso desta pesquisa, o contexto está relacionado com o ensino do português como língua estrangeira (PLE), em modalidade presencial, para estudantes dos cursos de formação superior Ciências da Informação e Engenharia de Produção da Universidade Nacional de Assunção e a rede social Facebook, utilizada como meio de extensão das atividades em sala de aula.

A matéria de português é ministrada como disciplina optativa para os dois cursos para estudantes que objetivam, em sua maior parte, fazer intercâmbio estudantil em universidades brasileiras ou cursar pós-graduação no Brasil e, em menor parte, obter melhores oportunidades no mercado de trabalho ou por gosto pessoal.

Foi proposta a participação na pesquisa a 90 estudantes, 60 de Engenharia de Produção e 30 de Ciências da Informação, dos quais 20 de Engenharia de Produção e 13 de Ciências da Informação aceitaram responder e participar, de forma livre e esclarecida, na pesquisa.

A Universidade Nacional de Assunção (UNA), fundada em 1889, conta com um campus central instalado na cidade de São Lourenço, Grande Assunção, e algumas faculdades espalhadas pela capital do país. A UNA possui cerca de 9.000 professores e 47.000 estudantes matriculados em 79 cursos de ensino superior. ${ }^{2}$

2 Todos os dados estatísticos da Universidade estão disponíveis em sua página web: http://www.una.py/index.php/la-universidad/estadisticas?showall=\&start=1 
A UNA tem concentrado esforços para seguir as recomendações da Conferência Mundial sobre a Educação Superior, que em seus diversos pontos realça a necessidade de melhoria da formação docente e de suas capacidades didáticas (UNESCO, 1998). Para o exercício do ensino no nível superior, a UNA exige dos professores capacitação ou especialização em Didática Universitária, curso oferecido em diversos departamentos da Universidade.

Minha experiência com esses cursos, inclusive como estudante, mostra que nem sempre estão contemplados, de maneira extensiva, os tópicos relacionados com o letramento digital de professores e estudantes.

Para preencher esta lacuna, algumas faculdades da UNA oferecem formação aos seus professores para o exercício do ensino na modalidade virtual, semipresencial ou presencial com o uso das novas tecnologias. Como professor de uma das faculdades que mais investem em estrutura de ensino on-line e como frequentador de muitos desses cursos, posso dizer que a temática predominante gira em torno do uso da Plataforma Moodle, adotada pela universidade como ambiente virtual de aprendizagem.

Os cursos são organizados em módulos e iniciam com a formação básica para o uso da Plataforma e seguem com o desenvolvimento de habilidades em diversos gêneros multimodais que o professor poderá utilizar por meio do Ambiente Virtual de Aprendizagem (AVA).

As habilidades desenvolvidas têm seu foco nas práticas de escrita e criação de conteúdos digitais como imagens e vídeos, além de objetos virtuais de aprendizagem criados com programas autorais. A formação dos estudantes está atrelada às iniciativas que esses professores promovem em suas salas de aula.

O uso das redes sociais nos processos de ensino e aprendizagem não fazem parte da cultura institucional, embora não haja nenhuma restrição a seu uso. A opção pelo Facebook se justifica pela familiaridade que os estudantes têm com esse meio, diferentemente da Plataforma Moodle, que exige apresentação. Também pelos esforços e práticas voltadas para o uso do Facebook na educação. Em setembro de 2015, Chris Cox, chefe de produtos do Facebook, anunciou nos Estados Unidos a criação de um aplicativo voltado para a educação com a qual professores, alunos e país poderiam interagir (WONG, 2015).

Também recentemente, a On CALL, revista especializada em aprendizagem de línguas mediada por computador, publicou dez dicas para o uso de grupos do Facebook: 
1) Apresentação do professor e do curso; 2) Facilitar a conversação sobre temas culturais polêmicos; 3) Intercambiar ideias sobre temas de ensaios; 4) praticar certos aspectos da gramática; 5) fazer enquetes; 6) publicar as datas limites de provas e de entrega de trabalhos; 7) publicar links para vídeos ou páginas web para estudos adicionais; 8) publicar anúncios urgentes e de grande relevância; 9) compartilhar fotos de grupo ou eventos e; 10) compartilhar arquivos (EDENS, 2015).

A importância do uso do Facebook na educação e na pesquisa educativa pode ser comprovada com o seguinte levantamento feito por Paiva $(2014)^{3}$ :

\begin{abstract}
O FB tornou-se objeto de pesquisa em várias áreas e, a cada dia, aparecem mais estudos sobre essa fascinante rede social. Em 02 de maio de 2014, o sistema de busca do Portal da Capes registrava 181.528 textos onde constava a palavra Facebook. Dez dias depois, já eram 182.663, o que demonstra o alto interesse no tema. (PAIVA, 2016, p.66).
\end{abstract}

Outra vantagem do Facebook é estar sempre acessível por multiplataformas: tablets, computadores e celulares, tornando a comunicação e a interação mais fáceis.

Os objetivos desse trabalho são descrever e analisar a articulação entre a aprendizagem do português como língua estrangeira e o desenvolvimento das habilidades digitais dos estudantes por meio de sua produção e interação no uso da rede social Facebook, como ambiente de aprendizagem. A pesquisa tem caráter qualitativo e utiliza a técnica de estudo de caso.

Para melhor compreensão, na sequência do artigo se apresentará o referencial teórico, que deu suporte à pesquisa, e que está constituído pela definição de letramento digital e pela definição do Facebook como Comunidade de Busca do Conhecimento (Community of Inquiry).

As questões relacionadas ao letramento digital são importantes para a articulação entre o ensino da língua e a formação para o século XXI, conforme propõe a Unesco em seu documento Declaração mundial sobre a educação superior no século XXI (1998).

O uso da teoria sobre Comunidade de Busca do Conhecimento, tal como proposto por Garrison, Anderson e Archer (2000), tem a virtude de contemplar a formação de comunidades e avaliá-las sob quatro dimensões integradoras, e não somente o aspecto cognoscível, que serão discutidas na sequência.

\footnotetext{
${ }^{3}$ O texto Facebook: um estado atrator na internet foi, originalmente, publicado em 2013 nos anais do $19^{\circ}$ Intercâmbio de Pesquisa em Linguística Aplicada, realizado na PUC-SP em 2013, tendo sido atualizado para apresentação na ANPOLL, em 2014. Os dados levantados contêm essa atualização.
} 
Creio importante destacar que o aspecto metodológico contempla um estudo exploratório que reduplica a enquete feita por Silva (2014) para estudantes brasileiros de espanhol na Universidade Cândido Mendes, Rio de Janeiro.

A aplicação da mesma enquete com estudantes paraguaios de português teve como objetivo, primeiro, verificar a predisposição deles para o uso das novas tecnologias, seu acesso às conexões de internet e sua disposição em utilizar a rede social Facebook como plataforma complementar às aulas presenciais e, segundo, se as conclusões, neste novo contexto, são compatíveis com Silva (2014) e, portanto, passiveis de orientarem tomadas de decisões semelhantes quanto ao letramento digital.

\section{LETRAMENTO DIGITAL}

Para entender o que vem a ser letramento digital, convém delinear o conceito de letramento, assumindo que definições claras e precisas não são possíveis, já que o conceito varia dependendo da perspectiva assumida (SOARES, 2002; SOARES, 2014).

Primeiro, associado com a alfabetização, o conceito de letramento se expande, nas últimas décadas do século XX, para referir-se às práticas de leitura e escrita por meio da "produção de textos de uma gama ampla e variada de gêneros textuais e de usos sociais da língua escrita" (SOARES, 2014, p.1).

Um conceito possível de letramento poderia ser a apropriação sociocontextualizada das capacidades de ler e escrever textos por meio de gêneros textuais. De acordo com Marcuschi (2012, p. 19), “os gêneros são formas sociais de organização e expressões típicas da vida cultural [...] não são categorias taxionômicas para identificar realidades estanques".

A partir da definição de letramento, podemos tratar de entender, ainda que de forma simplista, o letramento digital como "práticas sociais de leitura e produção de textos em ambientes digitais". (RIBEIRO; COSCARELLI, 2014, p.1).

O letramento digital implica no uso social de uma grande variedade de gêneros que estão disponíveis em computadores e aparelhos móveis, com ou sem o uso da internet, e no uso adequado e socialmente contextualizado das novas tecnologias com objetivos de comunicação. De acordo com Ribeiro e Coscarelli (2014, p.1) "ser letrado digital implica saber se comunicar em diferentes situações, com propósitos variados, nesses ambientes, para fins pessoais ou profissionais.”. 
Ribeiro e Coscarelli (2014) também assinalam que o letramento digital possui dois aspectos relevantes: o primeiro, relacionado com a capacidade e possibilidade de acesso à informação; o segundo, seria a característica multimodal das informações disponibilizadas nos ambientes digitais. Poder acessar e disponibilizar informações e compreender os gêneros multimodais também faz parte do letramento digital.

As práticas de letramento que envolvem as redes sociais exigem habilidades de compreensão e produção que se estendem para além dos textos verbais, abarcando imagens, vídeos, gráficos, infográfico etc. Para melhor avaliar essas competências digitais, tanto sob o aspecto do desenho que faz o professor quanto o da produção dos estudantes, podemos fazer uso de matrizes de habilidades digitais.

Utilizar matrizes facilita a construção de descritores pertinentes para a certificação de habilidades. Dias e Novais (2009, p.7) propõem, para a constituição de usuários competentes, uma matriz com base em quatro habilidades a seguir descritas:

- Utilizar diferentes interfaces;

- Buscar e organizar informações em ambiente digital;

- Ler hipertexto digital;

- Produzir textos (orais ou escritos) para ambientes digitais.

Além dessas quatro habilidades, Dias e Novais (2009) elaboraram uma divisão didática, por domínio, com a intenção de melhor organizar os descritores. A divisão foi feita com base em três elementos que obedecem a um desenho de aprendizagem: contato, compreensão e análise. Os descritores partem de aspectos mais sensoriais, seguindo os contornos da neurolinguística, e vão despertando funções mais complexas, relacionadas com a aprendizagem.

Quadro 01 - Quadro Matriz de letramento digital com seus descritores.

\begin{tabular}{|l|l|}
\hline \multicolumn{2}{|l|}{ 1. Utilizar diferentes interfaces } \\
\hline Grupo & Nome Descritor \\
\hline \multirow{4}{*}{ Contato } & Reconhecer a área de trabalho do computador \\
\cline { 2 - 2 } & $\begin{array}{l}\text { Reconhecer os programas básicos (editor de texto, cliente de e-mail, } \\
\text { navegador da internet). }\end{array}$ \\
\cline { 2 - 2 } & $\begin{array}{l}\text { Reconhecer o mouse, o teclado e outros elementos de interação entre } \\
\text { usuário e computador }\end{array}$ \\
\hline
\end{tabular}




\begin{tabular}{|c|c|}
\hline & $\begin{array}{l}\text { Identificar (a partir de ícones e da extensão) o programa gerador do } \\
\text { arquivo. }\end{array}$ \\
\hline & Reconhecer a barra de status dos diferentes programas \\
\hline \multirow{3}{*}{ Compreensão } & Inferir os botões e comandos padronizados pela interface. \\
\hline & $\begin{array}{l}\text { Perceber os processos pontuais realizados pelo computador a partir de } \\
\text { um comando dado }\end{array}$ \\
\hline & Compreender processos "em lote" realizados pelo computador \\
\hline \multirow{5}{*}{ Análise } & Analisar a estrutura dos menus e localizar um comando. \\
\hline & $\begin{array}{l}\text { Contrastar diferentes interfaces identificando padronizações de } \\
\text { comando semelhantes. }\end{array}$ \\
\hline & $\begin{array}{l}\text { Analisar os processos realizados pelo computador a partir de um } \\
\text { comando dado, observando alterações no formato do ponteiro do } \\
\text { mouse, nas barras de progresso visíveis na tela e nas mensagens } \\
\text { exibidas }\end{array}$ \\
\hline & Executar processos "em lote" \\
\hline & Julgar se a ação foi realizada da maneira mais eficaz. \\
\hline \multicolumn{2}{|c|}{ 2. Buscar e organizar informações em ambiente digital } \\
\hline Grupo & Nome Descritor \\
\hline \multirow{3}{*}{ Contato } & Reconhecer os mecanismos de busca e busca avançada. \\
\hline & $\begin{array}{l}\text { Reconhecer a forma de organização dos arquivos no computador } \\
\text { (unidades de disco - móveis e fixas -, pastas e subpastas). }\end{array}$ \\
\hline & $\begin{array}{l}\text { Reconhecer a forma de nomeação de sites e páginas na internet. } \\
\text { (www.nomedapagina.dominio.sigladopais/pastas/subpastas). }\end{array}$ \\
\hline \multirow{5}{*}{ Compreensão } & Selecionar palavras-chave adequadas \\
\hline & Construir um comando de busca eficaz. \\
\hline & Construir nomes eficazes para arquivos e pastas. \\
\hline & Selecionar/criar locais adequados para o armazenamento de arquivos. \\
\hline & Diferenciar endereços de páginas na internet. \\
\hline \multirow{3}{*}{ Análise } & $\begin{array}{l}\text { Relacionar a localização do arquivo ou programa no sistema de pastas } \\
\text { a seu conteúdo ou função. }\end{array}$ \\
\hline & Avaliar se a informação é pertinente ao objetivo de pesquisa. \\
\hline & Avaliar a confiabilidade da informação obtida. \\
\hline \multicolumn{2}{|c|}{ 3. Ler hipertexto digital } \\
\hline Grupo & Nome Descritor \\
\hline \multirow{5}{*}{ Contato } & $\begin{array}{l}\text { Reconhecer elementos (gráficos e linguísticos) que sinalizam a } \\
\text { presença de um link. }\end{array}$ \\
\hline & $\begin{array}{l}\text { Reconhecer os diversos gêneros que se organizam em hipertexto } \\
\text { digital. }\end{array}$ \\
\hline & Reconhecer a barra de status do navegador. \\
\hline & $\begin{array}{l}\text { Reconhecer recursos imagéticos da escrita hipertextual (emoticons, } \\
\text { gifs, banners etc). }\end{array}$ \\
\hline & Reconhecer que o hipertexto digital é composto de diversas mídias, \\
\hline
\end{tabular}




\begin{tabular}{|c|c|}
\hline \multirow{5}{*}{ Compreensão } & Localizar-se nas várias camadas que compõem um hipertexto. \\
\hline & Diferenciar texto autoral dos comentários relacionados a ele. \\
\hline & Inferir o conteúdo do link a partir de seu nó. \\
\hline & Descrever hierarquicamente a estrutura hipertextual. \\
\hline & Selecionar conteúdos pertinentes aos objetivos de leitura. \\
\hline \multirow{4}{*}{ Análise } & Relacionar o link ao conteúdo ou endereço ao qual leva. \\
\hline & $\begin{array}{l}\text { Relacionar som, imagem, vídeo, animação e linguagem verbal e } \\
\text { reconhecer os efeitos de sentido decorrentes de textos multimodais. }\end{array}$ \\
\hline & Avaliar a segurança do endereço ao qual leva o link. \\
\hline & Avaliar a confiabilidade do conteúdo do site. \\
\hline \multicolumn{2}{|c|}{ 4. Produzir textos (orais ou escritos) para ambientes digitais } \\
\hline Grupo & Nome Descritor \\
\hline \multirow[t]{2}{*}{ Contato } & $\begin{array}{l}\text { Reconhecer programas específicos para produção de texto no meio } \\
\text { digital (sejam eles multimodais ou não). }\end{array}$ \\
\hline & $\begin{array}{l}\text { Reconhecer elementos disponíveis por diferentes programas para } \\
\text { produção de textos. }\end{array}$ \\
\hline \multirow{4}{*}{ Compreensão } & $\begin{array}{l}\text { Compreender a forma como cada programa lida com objetos para } \\
\text { composição da escrita }\end{array}$ \\
\hline & $\begin{array}{l}\text { Organizar hierarquicamente uma estrutura hipertextual coerente ao } \\
\text { contexto de produção }\end{array}$ \\
\hline & Criar links adequados ao conteúdo ao qual fazer referência \\
\hline & $\begin{array}{l}\text { Conhecer, intepretar e respeitar as normas para publicação, divulgação } \\
\text { e reprodução de conteúdo on-line }\end{array}$ \\
\hline \multirow{5}{*}{ Análise } & Selecionar suporte e gênero adequados às condições de produção \\
\hline & $\begin{array}{l}\text { Escolher local adequado para armazenar e/ou publicar os textos } \\
\text { produzidos }\end{array}$ \\
\hline & $\begin{array}{l}\text { Organizar diferentes modalidades sígnicas para formar um texto ao } \\
\text { mesmo tempo "usável" e legível }\end{array}$ \\
\hline & $\begin{array}{l}\text { Avaliar a relevância do link criado, de acordo com as condições de } \\
\text { produção do texto }\end{array}$ \\
\hline & $\begin{array}{l}\text { Avaliar se o conteúdo produzido não fere as normas para publicação, } \\
\text { divulgação e reprodução de conteúdo on-line }\end{array}$ \\
\hline
\end{tabular}

Fonte: Simplificado a partir de: DIAS, M. C.; NOVAIS, A. E. Por uma matriz de letramento digital. Belo Horizonte: III Encontro Nacional sobre Hipertexto, 2009. Disponível em: https://goo.gl/4BgjBH

Entendemos que a base da Matriz de Letramento Digital, elaborada por Dias e Novais (2009), pode ser de grande valia para avaliação da produção dos estudantes, mesmo de nível superior, quando aplicada a uma rede social como o Facebook.

Tomando como base que "a linguagem humana evoluiu como um meio para formar alianças sociais e não para transmitir informações” (CUONZO, 2010, p.178 apud PAIVA, 2016), tivemos sempre em consideração que o estudo não fosse um mero 
processo de converter a rede social em simples suporte de conteúdo educacional, mas também em utilizá-la como forma de aproveitamento dos recursos digitais e linguísticos que transitam pela rede e que são familiares aos estudantes como meio de promover oportunidades de aprendizagem. Não há dúvida de que, para isso, é necessário ponderar e refletir sobre os conteúdos instrucionais disponibilizados, que devem ser coerentes com os objetivos pedagógicos do professor.

Os conteúdos utilizados na comunidade criada no Facebook foram, em parte, produzidos pelo professor, em parte aproveitados de outras fontes abertas como o Portal do Professor de Português como Língua Estrangeira ${ }^{4}$ e o Clica Brasil ${ }^{5}$ e, em parte, trazidas pelos próprios estudantes, que reduplicaram materiais de diversas fontes encontradas no próprio Facebook.

\section{O FACEBOOK COMO COMUNIDADE DE BUSCA DO CONHECIMENTO}

Como poderemos comprovar por meio da enquete realizada e explicitada mais abaixo, o uso das redes sociais, entre elas o Facebook, é corrente entre os estudantes, embora seja difícil precisar detalhadamente a assiduidade de uso que os estudantes fazem delas e se há, por parte do alunado, aceitação real em utilizar as redes sociais, originalmente pensadas para o entretenimento e comunicação, para fins educacionais.

Além da regularidade e aceitação de uso das redes sociais, por parte dos estudantes, para finalidades educacionais, que tratamos de conhecer por meio da enquete realizada e explicitada mais abaixo, também nos perguntamos se o Facebook comporta o papel de ambiente virtual de aprendizagem e se seu uso é viável para a construção de uma Comunidade de Busca do Conhecimento ${ }^{6}$, de acordo com o proposto por Garrison, Anderson e Archer (2000) e conforme detalhado na sequência, com duplo objetivo: desenvolvimento de habilidades de leitura e escrita de língua estrangeira, como objetivo principal, e o desenvolvimento de habilidades digitais, tais como trabalhar com arquivos de sons, imagens, fotos e vídeos, como objetivo secundário.

4 http://www.ppple.org/

5 http://laits.utexas.edu/clicabrasil/

${ }^{6}$ Comunidade de Busca do Conhecimento é uma das traduções possíveis e correntes para Community Of Inquiry. 
Nesse sentido, de acordo com Öztürk (2015), o Facebook pode ser uma ferramenta bastante útil em função de suas características:

\begin{abstract}
Todos os usuários podem dividir fontes de informação como as fotos, apresentações de cursos (slides), artigos e vídeos nas suas contas do Facebook. Por outro lado, discussões podem ser feitas por meio da troca de mensagens na timeline ou pelas ferramentas de bate-papo e email do Facebook..$^{7}$ (p. 21 tradução nossa).
\end{abstract}

Além dessas possibilidades, Öztürk (2015) argumenta que as redes sociais são naturalmente convidativas à cooperação e criação de novos produtos e são propícias para diminuir o sentimento de isolamento dos estudantes, além de criar um ambiente favorável a aproximação entre estudantes e professor, favorecendo a presença social.

Com relação ao uso da rede social Facebook, como Comunidade de Busca do Conhecimento, Öztürk diz que "examinando o potencial de grupos do Facebook como comunidades de busca de conhecimento e medindo seu impacto nas atividades acadêmicas poderia contribuir para a comunidade docente utilizar o Facebook em seus cursos." ${ }^{8}(2015$, p. 23 - tradução nossa).

A Communit of Inquiry (CoI), neste artigo traduzido como Comunidade de Busca do Conhecimento, de acordo com o modelo de Garrison, Anderson e Archer (2000), está composta por três dimensões ou presenças: a Presença Cognitiva (Cognitive Presence), a Presença Social (Social Presence) e a Presença Instrucional (Teaching Presence), que, em seu conjunto, conformam a Experiência Educacional (Educational Experience).

A relação entre a Presença Cognitiva e a Presença Instrucional se dá por meio da Seleção de Conteúdo (Selecting Contente); entre a Presença Cognitiva e a Presença Social, por meio do Apoio ao Discurso (Supporting Discourse) e; entre a Presença Social e a Presença Instrucional, por meio da Ambientação (Setting Climate), conforme o diagrama a seguir:

\footnotetext{
${ }^{7}$ all users can share sources of information such as pictures, course presentations (slides), articles, and videos on their Facebook accounts. On the other hand, discussions can be performed through message sharing on timelines or Facebook's real-time chat and e-mail tools.

8 examining the potential of Facebook groups as communities of inquiry, and measuring their impact on academic success could contribute to teaching staff in a way of utilizing Facebook in their courses
} 
Figura 1: Experiência Educacional em Comunidade de Busca do Conhecimento

\section{Community of Inquiry}

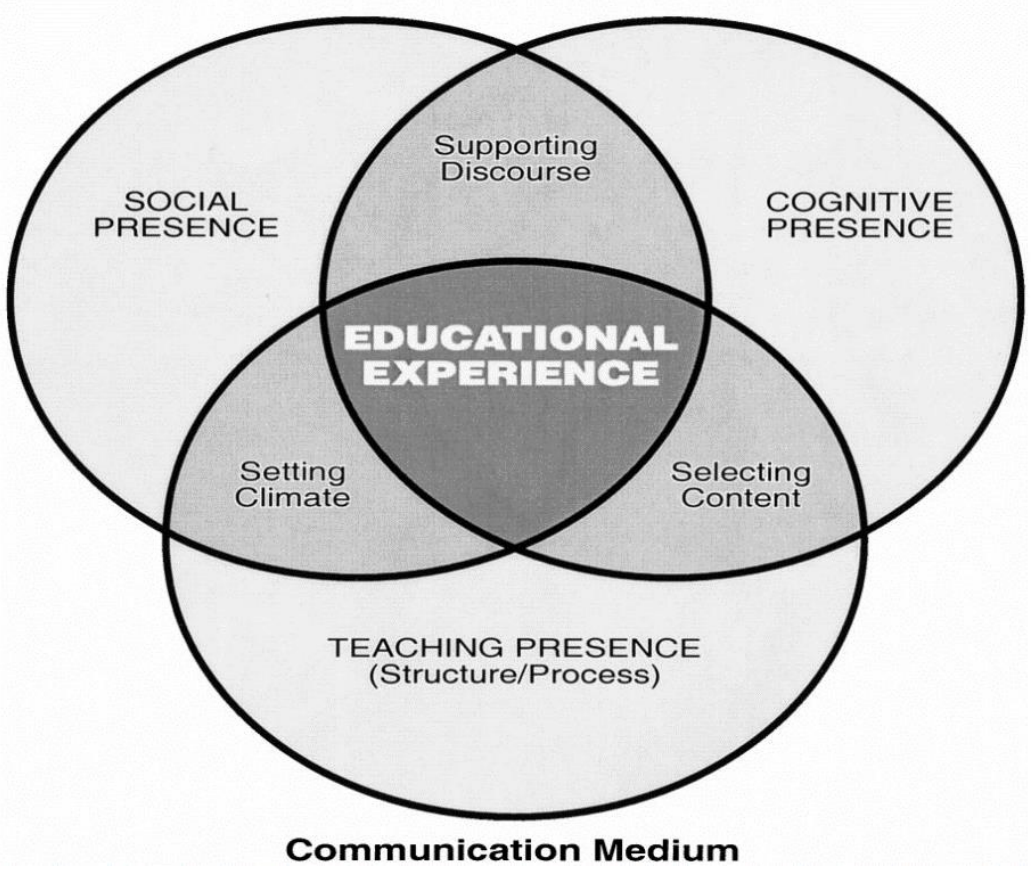

Fonte: Garrison, Anderson e Archer (2000, p.88).

A Presença Cognitiva é a de mais fácil alcance, quando se trata de educação superior, e está relacionada com a habilidade dos participantes da comunidade de construírem sentido por meio da intercomunicação.

A Presença Social está relacionada com a habilidade dos participantes em projetarem suas características pessoais, apresentando-se aos demais como "pessoas reais".

A Presença Instrucional tem duas funções gerais, que podem ser realizadas por qualquer dos participantes da comunidade, embora, em muitos casos, possa ser responsabilidade do professor. A primeira função relaciona-se ao desenho da experiência educacional, o que inclui seleção, organização e apresentação dos materiais didáticos, das atividades e das avaliações. A segunda função, relacionada com a facilitação do processo, é uma competência distribuída entre o professor e os demais componentes da comunidade (GARRISON; ANDERSON; ARCHER, 2000, p.89-90).

Todas as presenças ou dimensões possuem subcategorias, conforme o quadro abaixo: 
REVISTA X, Curitiba, volume 12, n.2,p.254-277,2017

Quadro 2: Dimensões ou presenças de uma Comunidade de Busca do Conhecimento.

\begin{tabular}{|l|l|l|}
\hline Presença Cognitiva & Presença Social & Presença Instrucional \\
\hline Evento Motivador & Expressões Emocionais & $\begin{array}{l}\text { Gerenciamento } \\
\text { Instrucional }\end{array}$ \\
\hline Exploração & Comunicações Abertas & $\begin{array}{l}\text { Construção } \\
\text { Entendimento }\end{array}$ \\
\hline Interação & Coesão de Grupo & Instrução Direta \\
\hline Resolução & & \\
\hline
\end{tabular}

Fonte: Garrison; Anderson; Archer, 2000, p. 90.

A Presença Cognitiva contempla o percurso de um ciclo experiencial completo no qual o Evento Motivador busca gerar uma sensação de perplexidade ou emotividade, muitas vezes relacionada com o humor e o discurso de si. O humor ajuda a construir os fatores de socialização e de aprendizagem, diminuindo as distâncias sociais e estabelecendo a ambientação. $\mathrm{O}$ discurso de si contribui com o desenvolvimento da presença social e incentiva os demais a participarem e falarem de si mesmos, estabelecendo um ambiente de maior confiança e satisfação.

A Exploração busca o intercâmbio e compartilhamento de informações e promove o passo seguinte: a Interação, que, por sua vez, busca conectar as ideias dos participantes e sintetizá-las. A Resolução tem como objetivo levar as ideias finais à aplicação e dá abertura para o surgimento de novas ideias.

As Expressões Emocionais, da Presença Social, utilizam, não raras vezes, emoticons como forma de expressão dos sentimentos dos participantes; as Comunicações Abertas, utilizam-se de expressões livremente declaradas, em tom respeitoso e de forma recíproca, alertando aos demais e reconhecendo sua contribuição, o que ajuda a modelar a aprendizagem. A Coesão de Grupo está relacionada com o compromisso de grupo, com o encorajamento à colaboração e à participação, priorizando os aspectos do grupo sobre os individuais.

A presença instrucional é essencial para criar um equilíbrio entre as presenças e, consequentemente, alcançar os objetivos propostos. Ela vai além das atividades do professor e pode ser assumida por participantes da comunidade.

Os autores identificam três categorias de presença instrucional: gerenciamento instrucional, construção do entendimento e instrução direta. A primeira categoria 
relacionada com o currículo, métodos de desenho e de avaliação, parâmetros temporais e meios. A segunda categoria se relaciona com a produção e aquisição de conhecimentos válidos. O processo deve ser desafiador para o sucesso da comunidade de busca do conhecimento. Neste aspecto, a participação de todos os componentes da comunidade é de muita importância.

A terceira categoria se relaciona com as indicações sobre o processo educativo e estão sob a reponsabilidade direta do professor, que deve facilitar a reflexão, guiar e sintetizar as discussões e confirmar o entendimento por meio de avaliações e feedbacks (GARRISON; ANDERSON; ARCHER, 2000, p. 90-1).

\section{METODOLOGIA}

O Grupo de Práticas de PLE no Facebook foi aberto para os alunos das faculdades Politécnica da Universidade Nacional de Assunção. Sessenta e três alunos, de dois grupos diferentes, se inscreveram voluntariamente na Comunidade como uma oportunidade de ampliar a exposição ao idioma alvo. Os estudantes assinaram termos de participação livre e esclarecida com o propósito de contribuírem com a geração dos dados para a pesquisa. Dos sessenta e três inscritos, trinta e três tiveram participação efetiva.

Figura 2 - Página inicial da comunidade aberta no Facebook.

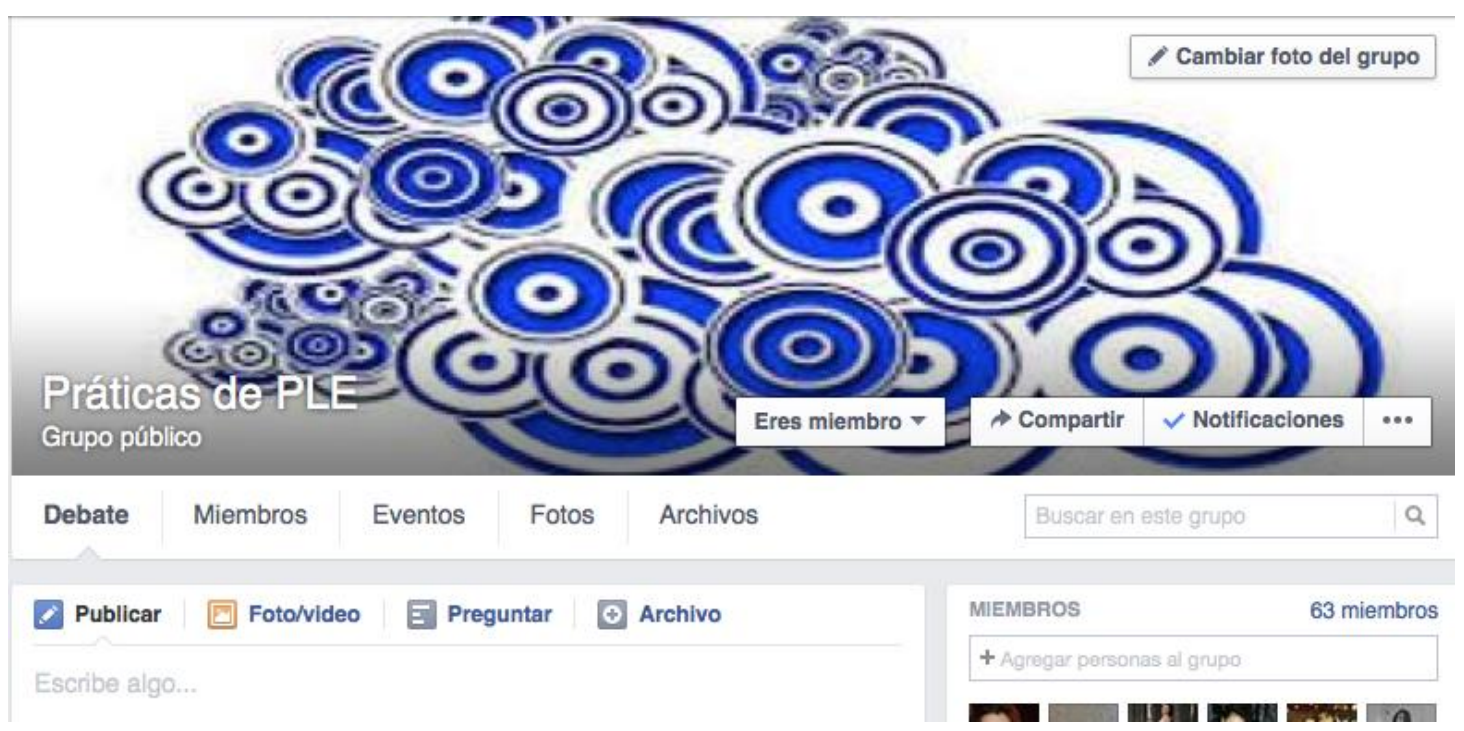

Fonte: Captura de tela do computador. Aceso em janeiro de 2017. 
Os materiais instrucionais utilizados na comunidade aberta no Facebook foram adaptados de materiais abertos disponíveis na internet sob a licença Creative Commons (REAs - Recursos Educacionais Abertos) e foram administrados pelo professor de acordo com o ciclo sugerido por Garrison, Anderson e Archer (2000) para a Presença Cognitiva. A Presença Social foi criada por meio de apresentações, comentários e publicações de materiais extras trazidos pelos alunos e a Presença Instrucional foi efetivada por meio do desenho de aula, pela seleção dos materiais publicados e pelas tarefas solicitadas.

A primeira preocupação, antes de criar a comunidade no Facebook, foi saber qual era a constância de uso das redes sociais por parte dos estudantes e se eles tinham experiência prévia em aprender idiomas por meio dessas redes.

Para isso partimos de 4 perguntas básicas que foram extraídas da pesquisa feita em Silva (2014) com alunos de espanhol da Universidade Cândido Mendes, no Rio de Janeiro: I) Com que frequência você utiliza as redes sociais Facebook e Twitter? II) Você acha que as redes sociais ajudam no aprendizado de outra língua? III) Você já aprendeu ou aprende algum idioma com a ajuda de alguma rede social? IV) Você acha que as redes sociais são importantes para aprender outro idioma?

A utilização das mesmas perguntas tem como propósito averiguar se, ao mudar o contexto de uso nesta pesquisa, há variação significativa dos resultados e com isso avaliar o potencial de transferibilidade e confirmabilidade da pesquisa feita por Silva (2014).

As respostas encontradas por Silva (2014) oriundas de seus 75 alunos brasileiros de espanhol, que participaram da pesquisa, foram as seguintes:

Figura 3: Primeira pergunta - Com que frequência você utiliza as redes sociais Facebook e Twitter?

\section{1) ¿Con que frecuencia utiliza los sitios de redes sociales (facebook, twitter)?}

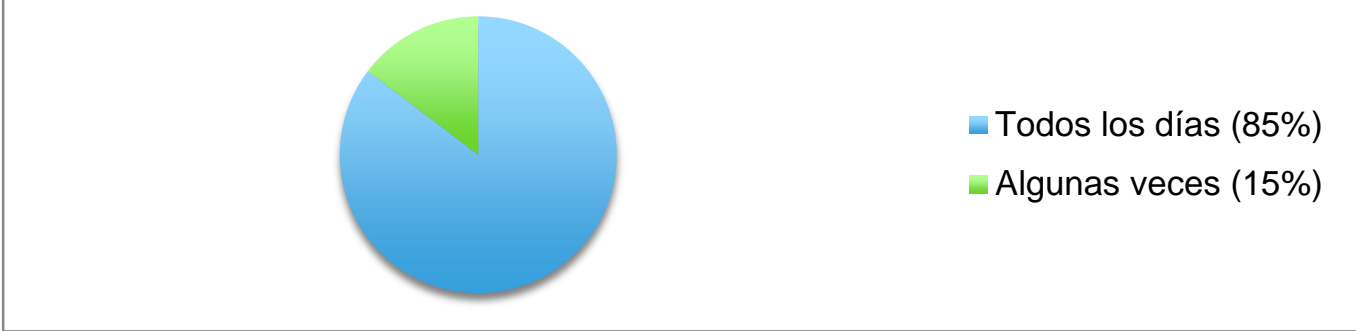

Fonte: Adaptada e traduzida de Silva (2014, p. 3). 
Figura 4: Segunda Pergunta - Você acha que as redes sociais ajudam no aprendizado de outra língua?

\section{2) ¿Crees qué las redes sociales ayudan en el aprendizaje de otra lengua?}

$$
\begin{aligned}
& \text {-Sí }(68 \%) \\
& \text { No }(9 \%) \\
& \text { Un poco }(22 \%)
\end{aligned}
$$

Fonte: Adaptada e traduzida de Silva (2014, p. 4).

Figura 5: Terceira Pergunta - Você já aprendeu ou aprende algum idioma com a ajuda de alguma rede social?

\section{3) ¿Ya aprendiste $o$ aprendes algún idioma con la ayuda de alguna red social?}

Fonte: Adaptada e traduzida de Silva (2014, p. 4).

Figura 6: Quarta Pergunta - Você acha que as redes sociais são importantes para aprender outro idioma?

\section{4) ¿Crees que las redes sociales son importantes para aprender otro idioma?}

$$
\begin{aligned}
& \text { Sí }(67 \%) \\
& \text { No }(4 \%) \\
& \text { Un poco }(29 \%)
\end{aligned}
$$

Fonte: Adaptada e traduzida de Silva (2014, p. 4).

Para Silva (2014), as redes sociais são um importante canal para o desenvolvimento da interação, da autonomia e do aprendizado colaborativo. 
Seguindo os mesmos procedimentos, fizemos uma enquete com alunos de português como língua estrangeira da Universidade Nacional de Assunção com o intuito de verificar se as conclusões de Silva (2014) são compatíveis com o contexto em que trabalhamos para orientar futuros trabalhos de práticas de letramento digital para o aprendizado de idiomas.

Utilizamos formulário do Google Drive para a construção da enquete. O ingresso ao grupo e a participação na enquete foi de caráter livre e a finalidade da participação, seu alcance e riscos foram informados a todos os alunos por meio de um termo de participação livre e esclarecida.

Para poder fazer uma comparação com Silva (2014), em agosto de 2015 a enquete esteve disponível para um universo de 90 alunos de português como língua estrangeira da Universidade Nacional de Assunção participantes da Comunidade de Práticas de PLE, dos quais 33 responderam às perguntas.

\section{APRESENTAÇÃO DOS DADOS 9}

Os dados obtidos da enquete foram os seguintes:

Figura 7: Com que frequência você utiliza as redes sociais (Facebook, Twitter)?

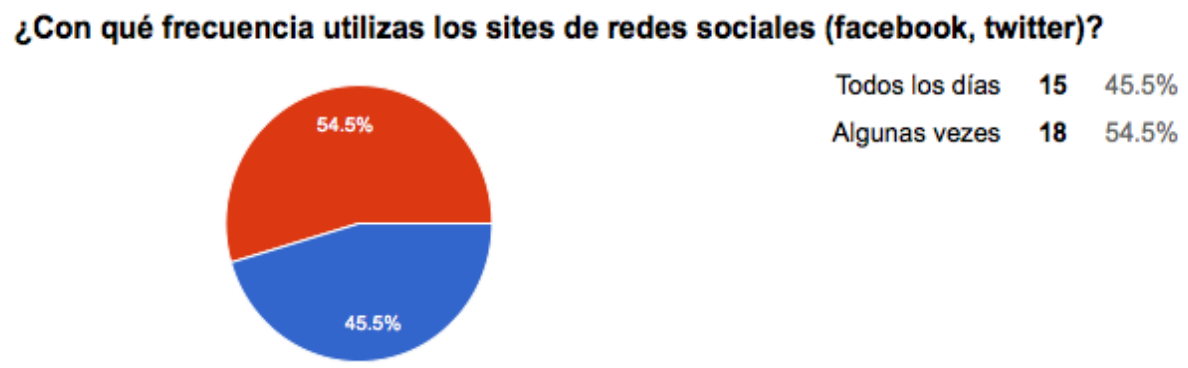

Fonte: Gráfico do Google Drive

\footnotetext{
${ }^{9}$ Todas as imagens relacionadas com os dados das enquetes foram geradas por Google Formulário.
} 
Figura 8: Você acha que as redes sociais ajudam no aprendizado de outra língua?

¿Crees qué las redes sociales ayudan en el aprendizaje de otra lengua?

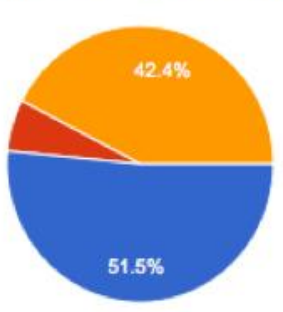

$$
\begin{array}{rrr}
\text { Si } & \mathbf{1 7} & 51.5 \% \\
\text { No } & \mathbf{2} & 6.1 \% \\
\text { Un poco } & \mathbf{1 4} & 42.4 \%
\end{array}
$$

Fonte: Gráfico do Google Drive

Figura 9: Você já aprendeu ou aprende algum idioma com ajuda de alguma rede social?

¿Ya aprendiste o aprendes algún idioma con la ayuda de alguna red social?

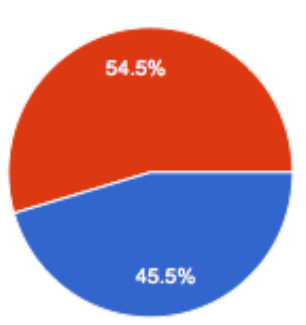

Si $15 \quad 45.5 \%$

No $18 \quad 54.5 \%$

Fonte: Gráfico do Google Drive

Figura 10: Você acha que as redes sociais são importantes para aprender outro idioma?

¿Crees que las redes sociales son importantes para aprender otro idioma?

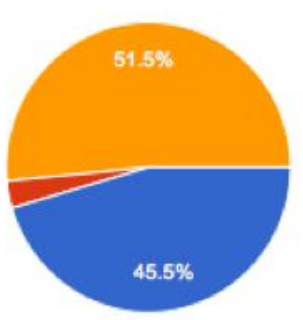

$$
\begin{array}{rrr}
\text { Si } & \mathbf{1 5} & 45.5 \% \\
\text { No } & \mathbf{1} & 3 \% \\
\text { Un poco } & \mathbf{1 7} & 51.5 \%
\end{array}
$$

Fonte: Gráfico do Google Drive

Uma descrição comparativa dos dados coletados nas duas universidades Universidade Cândido Mendes, Brasil, com 70 alunos de Espanhol como língua estrangeira (ELE) e na Universidade Nacional de Assunção, Paraguai, com 33 alunos de Português como língua estrangeira (PLE) mostram o seguinte quadro: 
Figura 11: Com que frequência utiliza as redes sociais (Facebook, Twitter)?

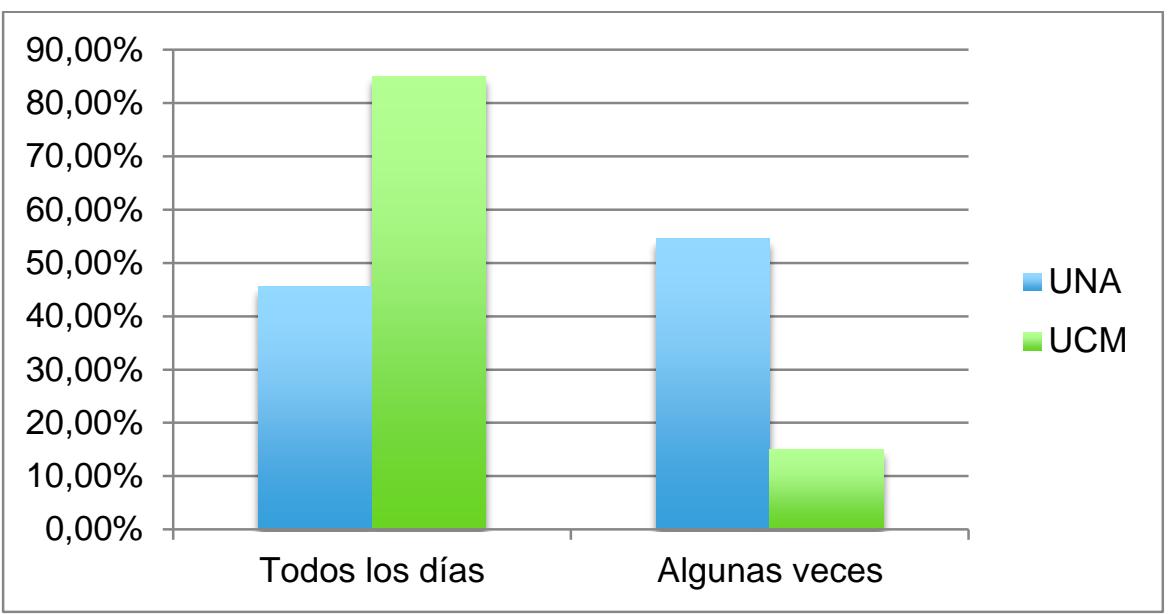

Fonte: Gráfico do Google Drive

Figura 12: Você acha que as redes sociais ajudam no aprendizado de outra língua?

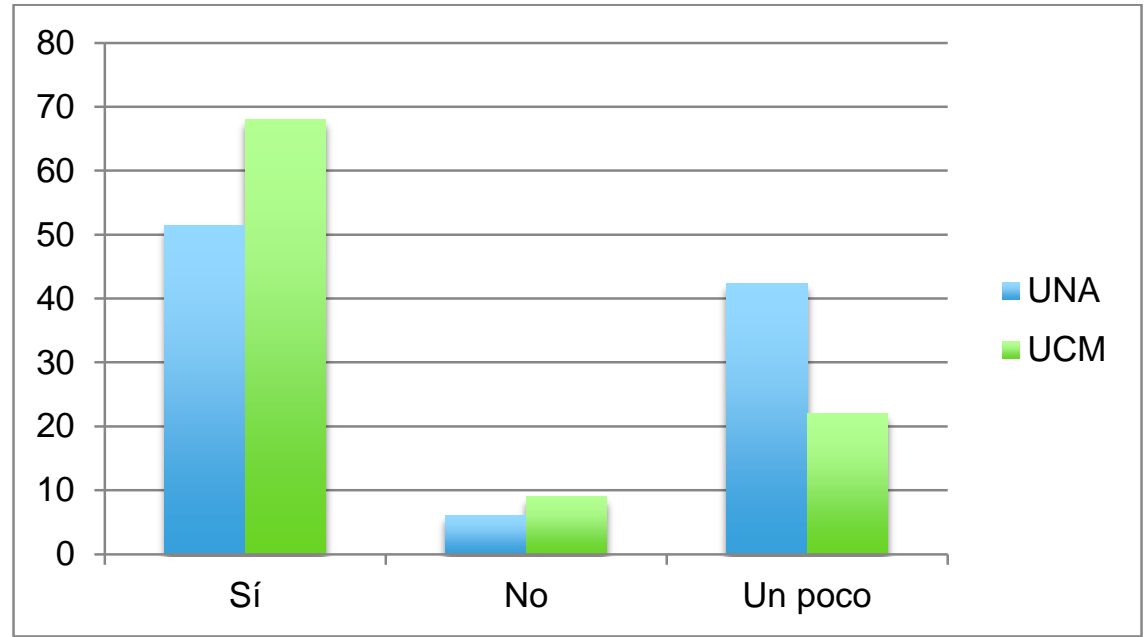

Fonte: Gráfico do Google Drive

Figura 13: Você aprendeu ou aprende algum idioma com ajuda de alguma rede social?

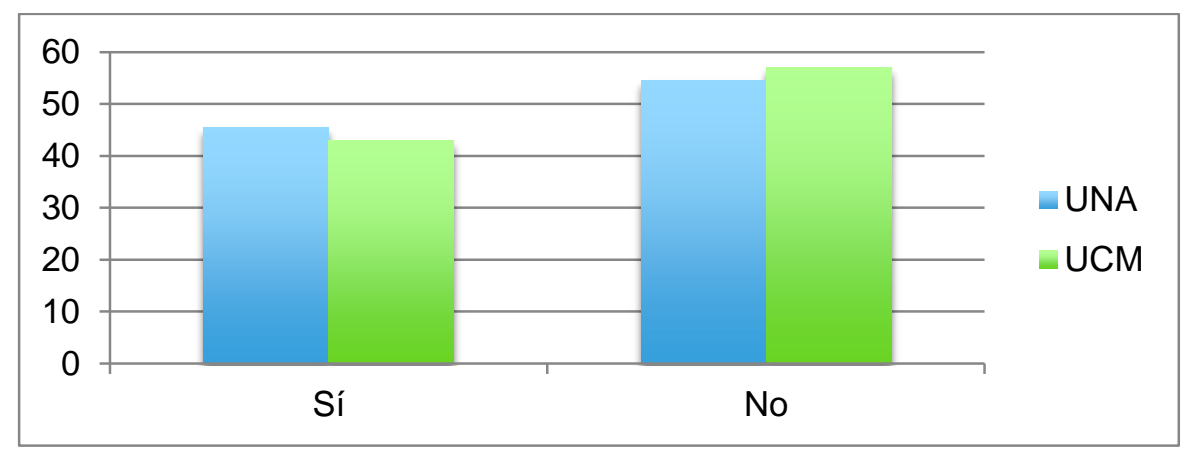

Fonte: Gráfico do Google Drive 
Figura 14: Você acha que as redes sociais são importantes para aprender outro?

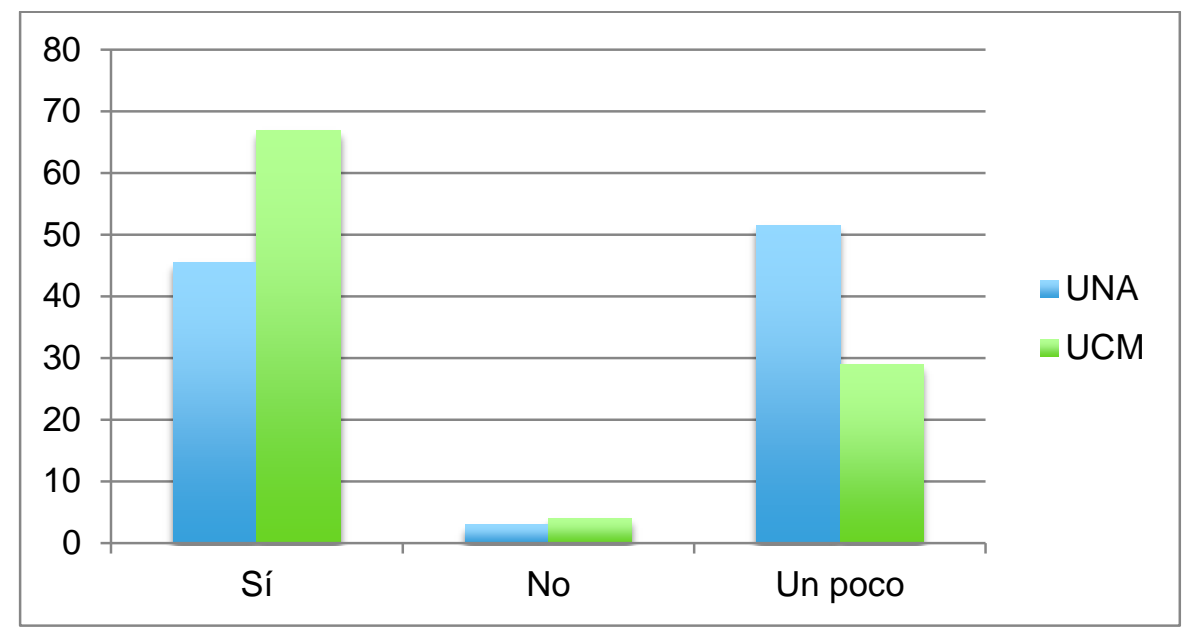

Fonte: Gráfico do Google Drive

De acordo com os resultados, podemos notar que há grande pertinência em incluir as redes sociais nas salas de aula já que $85 \%$ dos alunos de Silva (2014) e 45,5\% da UNA, no caso específico do Facebook, usam as redes sociais todos os dias. $68 \%$ dos alunos de Silva (2014) e 51,5\% da UNA acreditam que as redes sociais ajudam no processo de aprendizado de idiomas e $42,4 \%$ da UNA e $22 \%$ da UCM acreditam que ajuda um pouco.

Com relação as duas últimas perguntas, 43\% dos alunos de Silva (2014) e 45,5\% dos alunos da UNA já utilizaram as redes sociais para aprenderem idiomas e 67\% dos alunos de Silva (2014) e 45,5 \% da UNA acreditam na validade do uso das redes sociais para o ensino de idiomas.

Esses dados, considerando que as redes sociais são original e prioritariamente redes de entretenimento e não estão pensadas nem desenvolvidas para a educação, são bastante auspiciosos e motivadores.

Com base nos resultados da enquete, procedeu-se ao início da Comunidade de Busca do Conhecimento (GARRISON, ANDRESON e ARCHER, 2000), com base em um grupo fechado no Facebook.

Foi selecionado um tema relacionado com às aulas presenciais e ampliado na rede social por meio de uma tarefa sobre família, que foi avaliada como trabalho extraclasse.

A descrição dos eventos e a análise dos dados se deu com base nos descritores apontados nas teorias de Comunidade de Busca do Conhecimento (GARRISON, ANDRESON e ARCHER, 2000) e na Matriz de Habilidades Digitais (DIAS e NOVAIS, 2009). 
Com relação aos descritores e as presenças das comunidades de busca do conhecimento, podemos observar os seguintes exemplos selecionados.

Presença Cognitiva: o evento motivador teve dois aspectos, um presencial, a partir do estudo de relações familiares em sala de aula, e outro a partir de um vídeo falando sobre avós, disponível na internet, do acervo de Recursos Abertos da Universidade do Texas ${ }^{10}$. O tema foi explorado por meio de uma tarefa: a realização de uma árvore genealógica por parte de cada um dos participantes.

Figura 15.: Árvore Genealógica

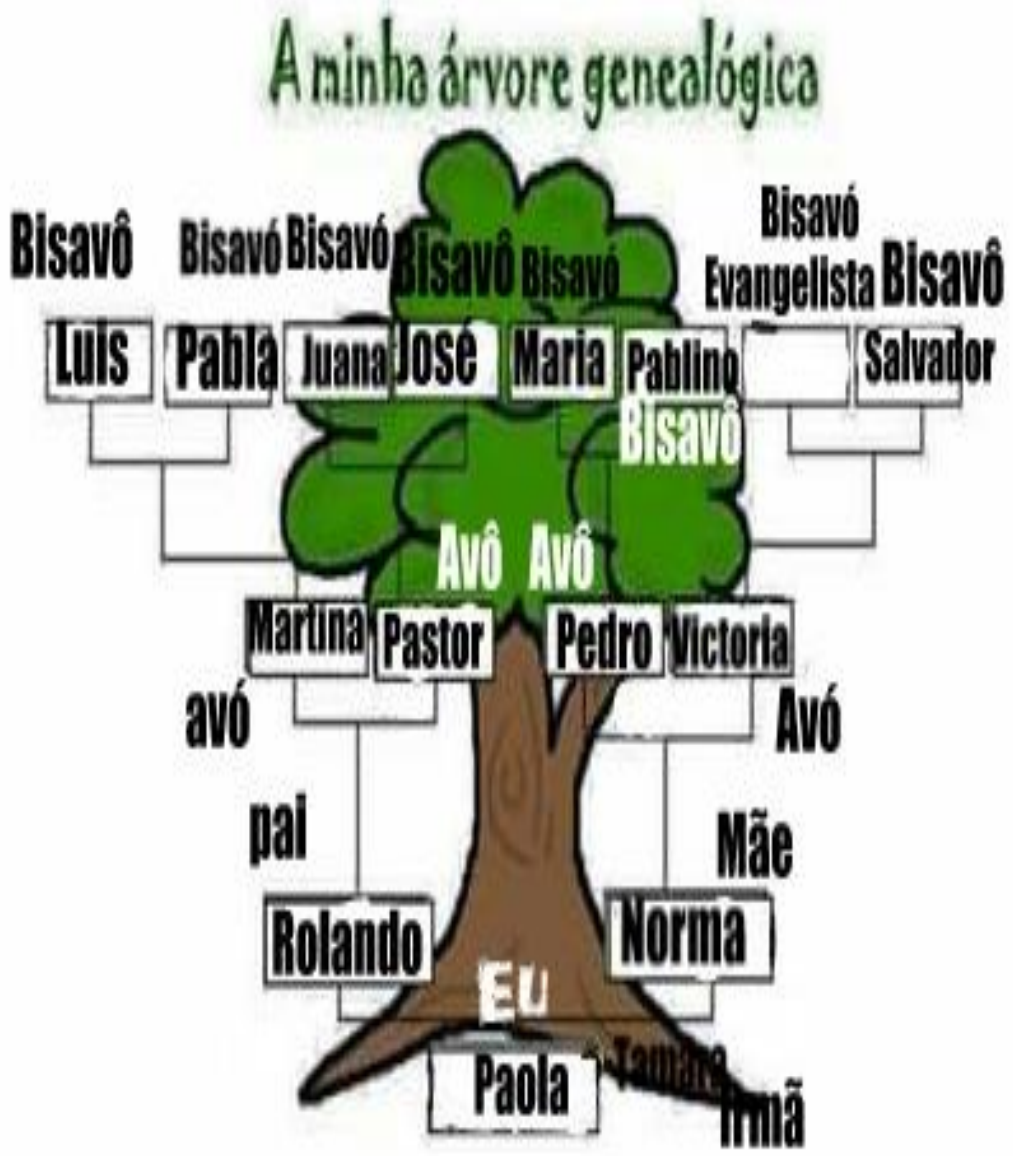

Fonte: Captura da tela do computador - Página da Comunidade no Facebook, acesso em janeiro de 2017

\footnotetext{
${ }^{10}$ http://coerll.utexas.edu/brazilpod/cob/lesson.php?p=15
} 


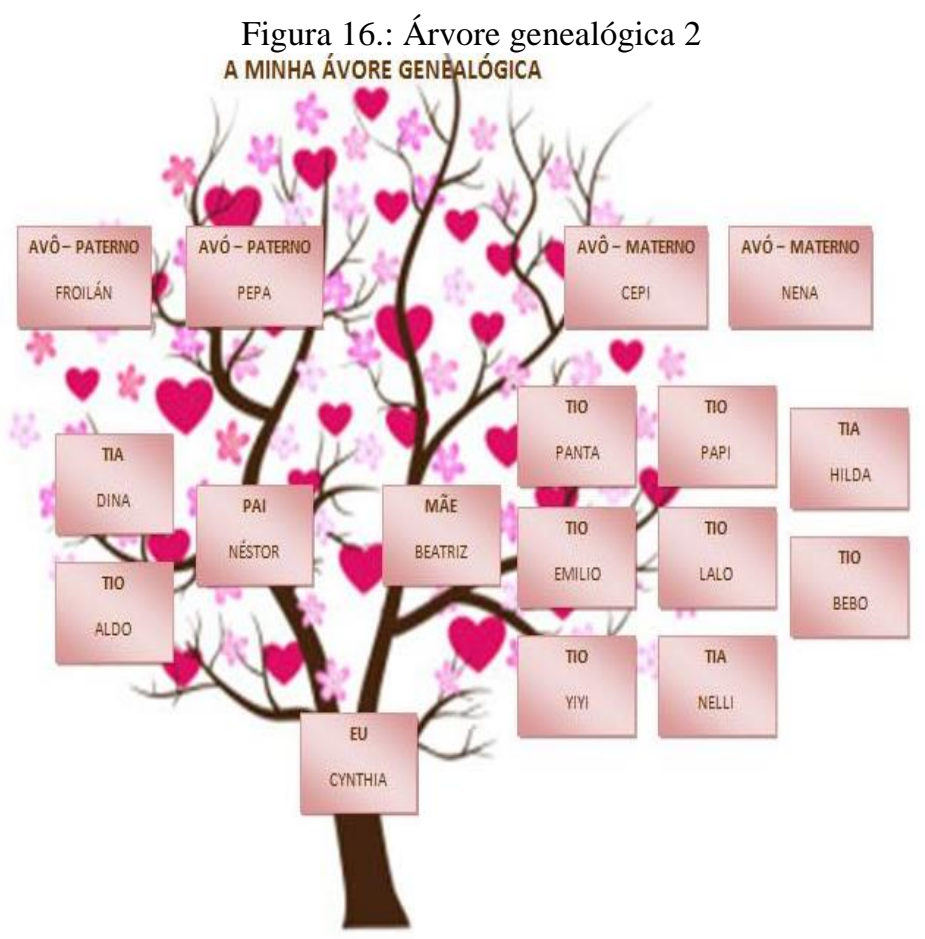

Fonte: Captura da tela do computador - Página da Comunidade no Facebook, acesso em janeiro de 2017.

Houve pouco intercâmbio de ideias e pouca interação nesta atividade, mas houve muita criatividade na elaboração do recurso digital para apresentação da árvore genealógica. A maioria dos estudantes preferiu trocar informações pessoalmente.

Com relação à Presença Social, há manifestações diretas de comentários de comunicação aberta, bem como o uso de emoticons.

Figura 17.: Troca de mensagens entre estudantes.

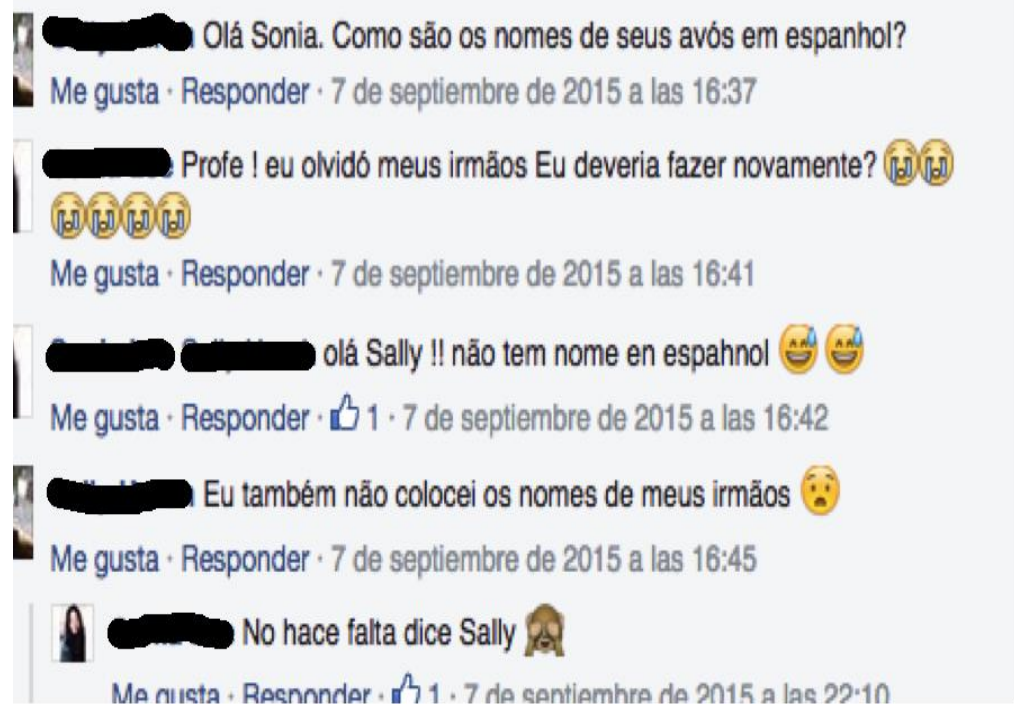

Fonte: Captura da tela do computador - Página da Comunidade no Facebook, janeiro de 2017. 
O Facebook favorece muito a presença social por meio de evidências de humor, apoio moral e expressão dos sentimentos, que geralmente congrega apoio e criam maior coesão de grupo, além de criar um clima mais ameno para a exposição pessoal.

A Presença Instrucional foi realizada pelo desenho de aprendizagem e com a negociação de sentido e feedback dado pelo professor em cada tarefa, além das instruções diretas, que foram as que mais tiveram retorno por parte dos estudantes.

Figura 18.: Troca de mensagens entre estudantes 2.
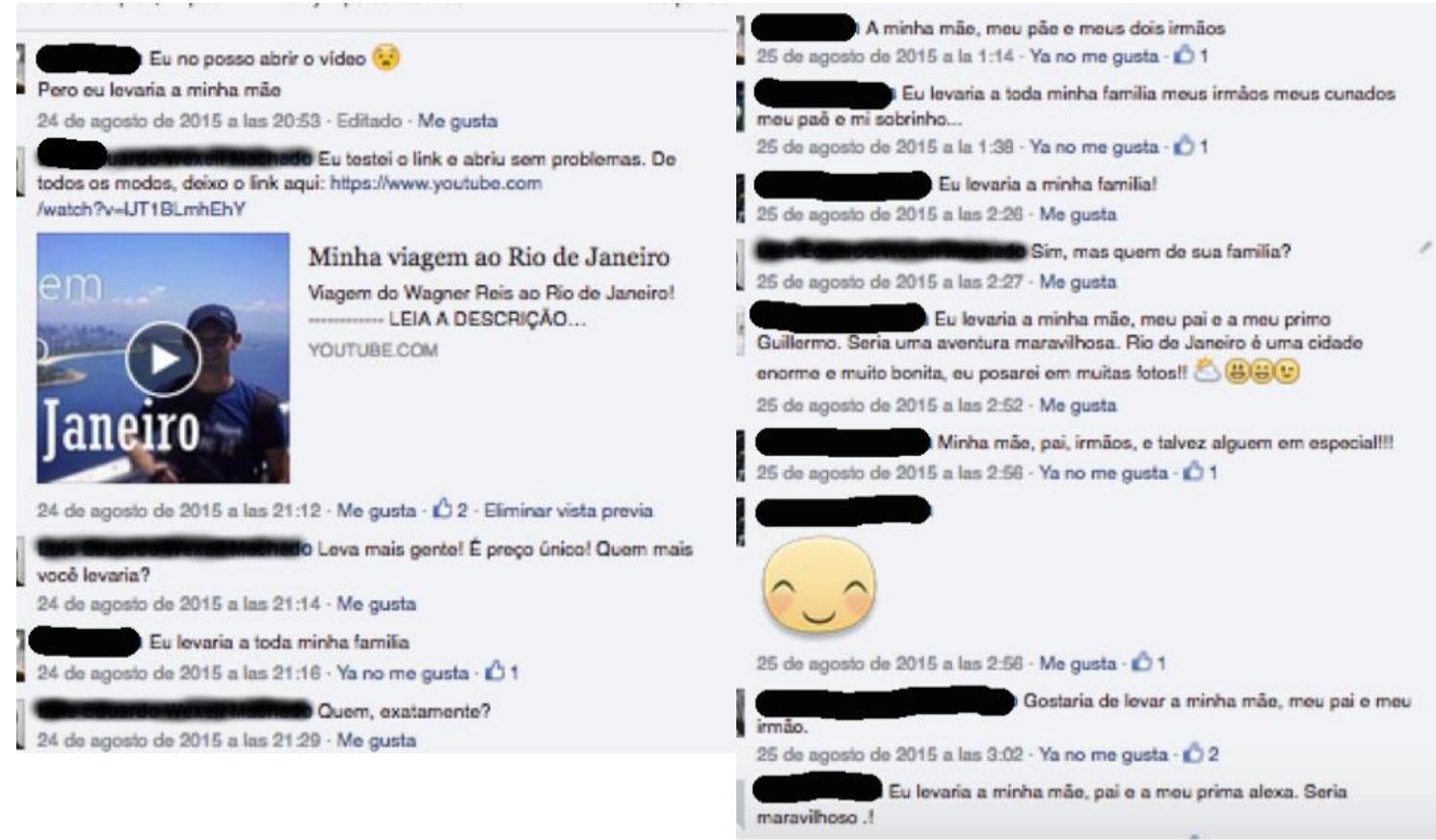

Fonte: Captura da tela do computador - Página da Comunidade no Facebook, janeiro de 2017.

Foram, em média, duas intervenções por estudante em cada instrução direta feita pelo professor. A instrução direta exigia resposta de cada um dos estudantes.

Os estudantes também apresentaram conteúdos em vídeo, com gravações familiares; gravações em áudio; imagens compartilhadas de outros sites do Facebook, principalmente memes em língua portuguesa e imagens relacionadas com ensino de vocabulário ou gramática do português. Alcançando o que Dias e Novais (2009) relacionam com competência em Letramento Digital: "Utilizar diferentes interfaces; buscar e organizar informações em ambiente digital; ler hipertexto digital; produzir textos (orais ou escritos) para ambientes digitais" (2009, p.7). 


\section{CONCLUSÃO}

De acordo com os dados obtidos e com base em Soares (2002, p.152), sobre a tela do computador como "espaço de escrita e de leitura" que demanda "novas formas de acesso à informação", "novos processos cognitivos", "novas formas de conhecimento", "novas maneiras de ler e de escrever", e que sinalizam a urgência de um novo letramento, isto é, de um novo estado ou condição para aqueles, incluídos digitalmente, que exercem práticas de escrita e de leitura na tela, podemos dizer que há potencial pedagógico na utilização do Facebook como comunidade de busca do conhecimento e como oportunidade de desenvolvimento do letramento digital na aprendizagem de línguas estrangeiras.

Os estudantes produziram imagens, fotos modificadas e vídeos tratando o tema da família. Também ficaram evidentes as Presenças Social e Instrucional com bom nível de interação. A Presença Cognitiva, muito importante por se tratar de ensino superior, ficou aquém das demais já que embora os estudantes completassem as atividades, não houve muita interação online e os estudantes preferiram dialogar diretamente de forma presencial.

Esse fato requer maior reflexão e pesquisa para identificar se trata-se de uma questão de hábito, tanto por não estarem acostumados a utilizarem o Facebook como ambiente virtual de aprendizagem quanto por sentirem-se mais cômodos em interagir pessoalmente ou se o desenho de aprendizagem precisa ser melhorado para incentivar a interação online.

\section{REFERÊNCIAS}

DIAS, M. C.; NOVAIS, A. E. Por uma matriz de letramento digital. Belo Horizonte: III Encontro Nacional sobre Hipertexto, 2009.

EDENS, J. Top 10 uses of a private Facebook group for your students. 2015. On CALL Newsletter.

Disponível em: <http://newsmanager.commpartners.com/tesolcallis/issues/2015-0825/4.html >. Acesso em: 15 fev. 2017.

GARRISON, D. R.; ANDERSON, T.; ARCHER, W. Critical Inquiry in a Text-Based Environment: Computer Conferencing in Higher Education In: The Internet and Higher Education Alberta: University of Alberta, 2000 
MARCUSCHI, L.A. Gêneros Textuais emergentes no contexto da tecnologia digital. In: Marcuschi L.A.; XAVIER, A. C. Hipertexto e gêneros digitais. São Paulo: Cortez, $3 \mathrm{a}$ edição, 2012.

ÖZTÜRK, Ebru. Facebook as a new Community of Inquiry environment: an investigation in terms of academic achievement and motivation. Journal of Baltic Science Education, v.14, n.1,pp. 20-33, 2015.

PAIVA, V. L. M. de O. Facebook: um estado atrator na internet. In: ARAÚJO, J.; LEFFA; V. (Orgs.) Redes sociais e ensino de línguas: o que temos de aprender? São Paulo: Parábola, 2016. Pp.65-80.

RIBEIRO, A. E. Como crianças percebem o leiaute antes de aprenderem a ler. São Paulo: Alfa, 54, p. 505-531, 2010.

RIBEIRO, A.E.; COSCARELlI, C. V. Letramento Digital. In.: FRADE, I. C. A. S., COSTA VAL, M. G. F., BREGUNCI, M. G. C. Glossário Ceale: termos de alfabetização, leitura e escrita para educadores. Belo Horizonte: FaLe UFMG, 2014.

SILVA E. T. da. La enseñanza de idiomas mediado por el ciberespacio: el uso de las redes sociales como aporte de la enseñanza. EVIDOSOL e VII CILTEC-Online junho/2014.

SOARES, Magda. Letramento. In.: FRADE, I. C. A. S., COSTA VAL, M. G. F., BREGUNCI, M. G. C. Glossário Ceale: termos de alfabetização, leitura e escrita para educadores. Belo Horizonte: FaE UFMG, 2014.

Novas práticas de leitura e escrita: letramento na cibercultura. Educ. Soc. v.23, $\mathrm{n} .81$ Campinas. Dez. 2002. Disponível em: http://www.scielo.br/pdf/es/v23n81/13935.pdf Acesso em 15/02/2017.

UNESCO. Declaración mundial sobre la educación superior en el siglo XXI: visión y acción. Paris: UNESCO, 1998. Disponível em: http://www.unesco.org/education/educprog/wche/declaration_spa.htm; tradução ao português da Universidade de São Paulo, disponível em: https://goo.gl/6dZIga

WONG, Queenie. Facebook creates free education tools. 2015. ESchool News. Disponível em: <http://www.eschoolnews.com/2015/09/09/facebook-education-tools809/>. Acesso em: 15 fev. 2017. 